Article

\title{
The Prognostic Values of PARP-1 Expression in Uveal Melanoma
}

\author{
Malgorzata Gajdzis ${ }^{1, *}$, Stamatios Theocharis ${ }^{2,3}$, Jerzy Klijanienko ${ }^{3}$, Nathalie Cassoux ${ }^{4}$, Sophie Gardrat ${ }^{5}$, \\ Piotr Donizy ${ }^{6} \mathbb{D}^{\mathbb{0}}$, Radoslaw Kaczmarek ${ }^{1}$ and Pawel Gajdzis ${ }^{3,6}$
}

1 Department of Ophthalmology, Wroclaw Medical University, 50-556 Wroclaw, Poland; radoslaw.kaczmarek@umed.wroc.pl

2 First Department of Pathology, National and Kapodistrian University of Athens, 15772 Athens, Greece; theocharis@ath.forthnet.gr

3 Department of Pathology, Curie Institute, 75005 Paris, France; jerzy.klijanienko@curie.fr (J.K.); pawel.gajdzis@umed.wroc.pl (P.G.)

4 Department of Ophthalmology, Institut Curie, 75005 Paris, France; nathalie.cassoux@curie.net

5 Department of Biopathology, Institut Curie, PSL Research University, 75005 Paris, France; sophie.gardrat@curie.net

6 Department of Pathomorphology and Oncological Cytology, Wroclaw Medical University, 50-556 Wroclaw, Poland; piotrdonizy@wp.pl

* Correspondence: gosiagajdzis@gmail.com; Tel.: +48-71-736-4300

Citation: Gajdzis, M.; Theocharis, S.; Klijanienko, J.; Cassoux, N.; Gardrat, S.; Donizy, P.; Kaczmarek, R.; Gajdzis, P. The Prognostic Values of PARP-1 Expression in Uveal Melanoma. Cells 2021, 10, 285. https://doi.org/ $10.3390 /$ cells 10020285

Academic Editors: Péter Bay and Tibor Pankotai

Received: 31 December 2020

Accepted: 27 January 2021

Published: 31 January 2021

Publisher's Note: MDPI stays neutral with regard to jurisdictional claims in published maps and institutional affiliations.

\begin{abstract}
Background: Uveal melanoma is the most common primary intraocular malignancy in adults. In advanced cases, the prognosis is very poor. Thus far, no effective methods of pharmacotherapy of this cancer have been found. The aim of the study was to evaluate the expression of PARP-1, the best-known member of the family of poly(ADP-ribose) polymerases, in uveal melanoma and its associations with clinicopathological parameters, overall survival, and disease-free survival. Methods: The study included 91 patients who underwent enucleation due to uveal melanoma. PARP-1 expression was assessed by immunohistochemistry. Results: High PARP-1 expression was associated with more frequent chromosome 3 loss, higher histopathological grade, bigger tumor size, and absence of intrascleral extension. High PARP-1 expression was associated with shorter overall survival time and disease-free survival time. Conclusions: The above findings indicate that high expression of PARP-1 can be considered as an unfavorable prognostic factor in uveal melanoma.
\end{abstract}

Keywords: PARP; PARP-1; uveal melanoma; immunohistochemistry

\section{Introduction}

Uveal melanoma (UM) is the most common primary intraocular malignancy in adults. With a mean age-adjusted incidence of 5.1 cases per million per year, it appears to be a rare disease, but is important in ophthalmic practice [1]. The reason is the high tendency to metastasize-about $50 \%$ of patients develop metastasis, often many years after the treatment of the primary tumor [2]. Five-year survival rates vary considerably depending on the stage of the disease [3]. However, in the case of systemic disease, the prognosis worsens dramatically. Only $8 \%$ patients with metastatic melanoma survive two years [4]. The meta-analysis of 29 studies conducted during 1988-2015 proved how serious the problem is in the treatment of UM. It showed that the mean progression-free survival and overall survival did not change over the years, regardless of the treatment method used [4]. For this reason, numerous studies are being conducted looking for new prognostic factors as well as potential new therapeutic options.

Poly(ADP-ribose) polymerases (PARP) are a family of proteins involved in a number of cellular processes. These enzymes are present in all eukaryotes except yeast [5]. Of the 17 known PARP homologs in human, PARP-1 is the best known and most extensively studied. The most important function of PARP-1 is participation in the DNA repair processes [5]. 
In the case of minor DNA damage, the enzyme detects damaged areas and participates in the chromatin remodeling process [6,7]. Moreover, PARP-1 recruits other proteins to DNA damage sites [8-10]. Thus, it engages in such DNA repair mechanisms as base excision repair (BER), nucleotide excision repair (NER), DNA mismatch repair (MMR), and maintenance of replication fork stability [11]. It also participates in non-homologous end-joining and homologous recombination-pathways that ensure the repair of DNA double-strand breaks [12,13]. At moderate levels of DNA damage, PARP-1 activation results in cleavage of PARP-1 by caspases into two fragments, which is a hallmark of apoptosis and might modulate the apoptotic process [14]. In the case of severe DNA damage, over-activation of PARP-1 occurs, leading to programmed necrotic cell death [15].

It is also worth emphasizing that PARP-1 is one of the main nicotinamide adenine dinucleotide (NAD) consuming enzymes. NAD is an essential cofactor of redox enzymes and a substrate for enzymes that regulate DNA repair, gene expression, and the stress response [16]. Changes in PARP-1 expression, both during the course of the disease and during treatment with PARP inhibitors, may thus have a much more complex effect on cell metabolism.

Apart from the important role in DNA repair, PARP-1 also participates in the regulation of inflammatory processes. PARP-1 promotes inflammatory responses by positively regulating the pro-inflammatory Nuclear Factor- $\mathrm{kB}$ (NF- $\mathrm{kB}$ ) transcription factors [17]. NF- $\mathrm{kB}$ activation pathways are involved not only in inflammation but also in immunity and carcinogenesis and can lead to tumor cell proliferation, invasion, angiogenesis, and metastasis [18].

The enzyme-involved in numerous DNA repair processes, regulating cell death in the event of excessive damage, and additionally affecting chronic inflammation-must be of interest in the context of carcinogenesis. For this reason, in recent years, we observed an increase in the interest of PARP-1. There are numerous studies on the mechanisms of action and the possibility of using its expression in the assessment of prognosis in various diseases, particularly in cancer. It is also being investigated as a target point for therapy. In this study, we examined the expression level of PARP-1 in primary UM. The aim of the study was to assess whether the degree of expression could be a prognostic factor in this relatively rare but deadly cancer. Additionally, we assessed if PARP-1 could be useful for molecular-targeted therapy.

\section{Materials and Methods}

\subsection{Patients}

Medical records and archive histopathological specimens of 91 patients with primary UM diagnosed during 2007-2008 at the Curie Institute, Paris, France were used in the study. All patients underwent enucleation as primary treatment. Patients with prior radiotherapy or chemotherapy were excluded from the study. Cases with too small amount of tumor cells in paraffin-embedded tissue were also excluded. The documented follow-up period was up to 115 months.

In our study, we considered clinicopathological parameters that are well-known prognostic factors in UM: chromosome 3 loss, presence of metastasis, mitotic activity, grading, intra- or extra-scleral extension, ciliary body involvement, tumor size, and patients' age. Chromosome 3 loss analysis was assessed by CGH (comparative genomic hybridization), FISH (fluorescence in situ hybridization), or karyotype studies. It was available for 67 patients. Mitotic activity was assessed on X400 in 40 fields using hematoxylin and eosin staining. It was determined in 89 cases-in the remaining two cases, there was too much melanin in the tumor cells, preventing reliable evaluation. The histological grading was based on conventional criteria: G1, spindle cell uveal melanoma ( $>90 \%$ spindle cells); G2, mixed cell uveal melanoma ( $>10 \%$ epithelioid cells and $<90 \%$ spindle cells); and G3, epithelioid cell uveal melanoma ( $>90 \%$ epithelioid cells). Other data-presence of metastasis, tumor size, age, and tumor localization-were obtained from the medical documentation. 
The study was conducted in accordance with the Declaration of Helsinki, and it was approved by the Institutional Review Board of the Wroclaw Medical University, Poland (KB-508/2019-approval for statutory subsidy). Due to the retrospective nature of the studies and the lack of impact on the treatment of patients, it was not necessary to obtain informed consent.

\subsection{Immunohistochemistry}

Immunohistochemical studies were performed on the tissue materials fixed in $10 \%$ buffered formalin and embedded in paraffin blocks. Freshly prepared tissue sections (4 $\mu \mathrm{m}$ thick) were deparaffinized, rehydrated and then subjected to epitope retrieval. Commercially available antibodies against PARP-1 (clone: sc-74470 (B10), dilution: 1:50, Santa Cruz Biotechnology, Santa Cruz, CA, USA) and Autostainer 48 (DAKO) were utilized for immunohistochemical staining. Liquid Permanent Red (DAKO) was used as detection system. Red chromogen enabled visualization in tissues containing a large amount of melanin. As a positive control, human placenta and cutaneous melanoma tissues were used, as recommended by the manufacturer. The negative (isotype) controls were processed using FLEX Mouse Negative Control (DAKO).

Expression of PARP-1 was assessed by two independent pathologists (P.G and P.D.) with full agreement, based on observation of at least 1000 cells in each case. Only nuclear expression was considered positive. In some cases, there were also weak cytoplasmic expression in the tumoral cells, but it was interpreted as nonspecific and nondiagnostic. Scoring of PARP-1 immunostains was done using a semi-quantitative scale of the ImmunoReactive Score (IRS) $[19,20]$. It is expressed as multiplication between positive cells proportion score (0-4) and staining intensity score (0-3). For percentage of positive cells: $0=$ no positive cells; $1=<10 \%$ positive cells; $2=10-50 \%$ positive cells; $3=51-80 \%$ positive cells; and $4=>80 \%$ positive cells. For intensity of staining: $0=$ no color reaction; $1=$ mild reaction; 2 = moderate reaction; and 3 = intense reaction. The final, integrated scores ranged 0-12 [21]. For the purposes of statistical analysis, the cut-off point was set at $\geq 4$ (low expression for 0-3 and high expression for 4-12). Examples of PARP-1 staining in tumoral cells are presented in Figure 1A-D. The determination of the cut-off point resulted from the statistical analysis as well as literature review on PARP-1 expression. The cut-off point for percentage of positive cells was set at $\geq 3$ (low percentage for $0-2$ and high percentage for 3-4). For intensity of staining, the cut-off point was set at $\geq 2$ (low intensity for $0-1$ and high intensity for 2-3).

\subsection{Statistical Analysis}

To assess the associations between PARP-1 expression and clinicopathological factors, Chi-square and U Mann-Whitney test were used. Overall survival curves and diseasefree survival curves were constructed using the Kaplan-Meier estimator. The differences between the curves were compared on the basis of the log-rank test. A p-value less than or equal to 0.05 was considered statistically significant. All statistical analyses were performed in the Statistica 13 software (StatSoft Polska, Krakow, Poland).

\section{Results}

Tissue materials from tumors from 91 patients (including 55 women and 36 men) were used in the study. The average age was 63 years. Clinicopathological characteristics of the study group are presented in Table 1. Low PARP-1 expression was noted in 35 cases $(38.5 \%)$, while high in 56 cases $(61.5 \%)$. The intensity of the reaction was described as low in 32 cases (35\%) and high in $59(65 \%)$. The percentage of positive cells was low in 47 cases (52\%) and high in 44 (48\%). 


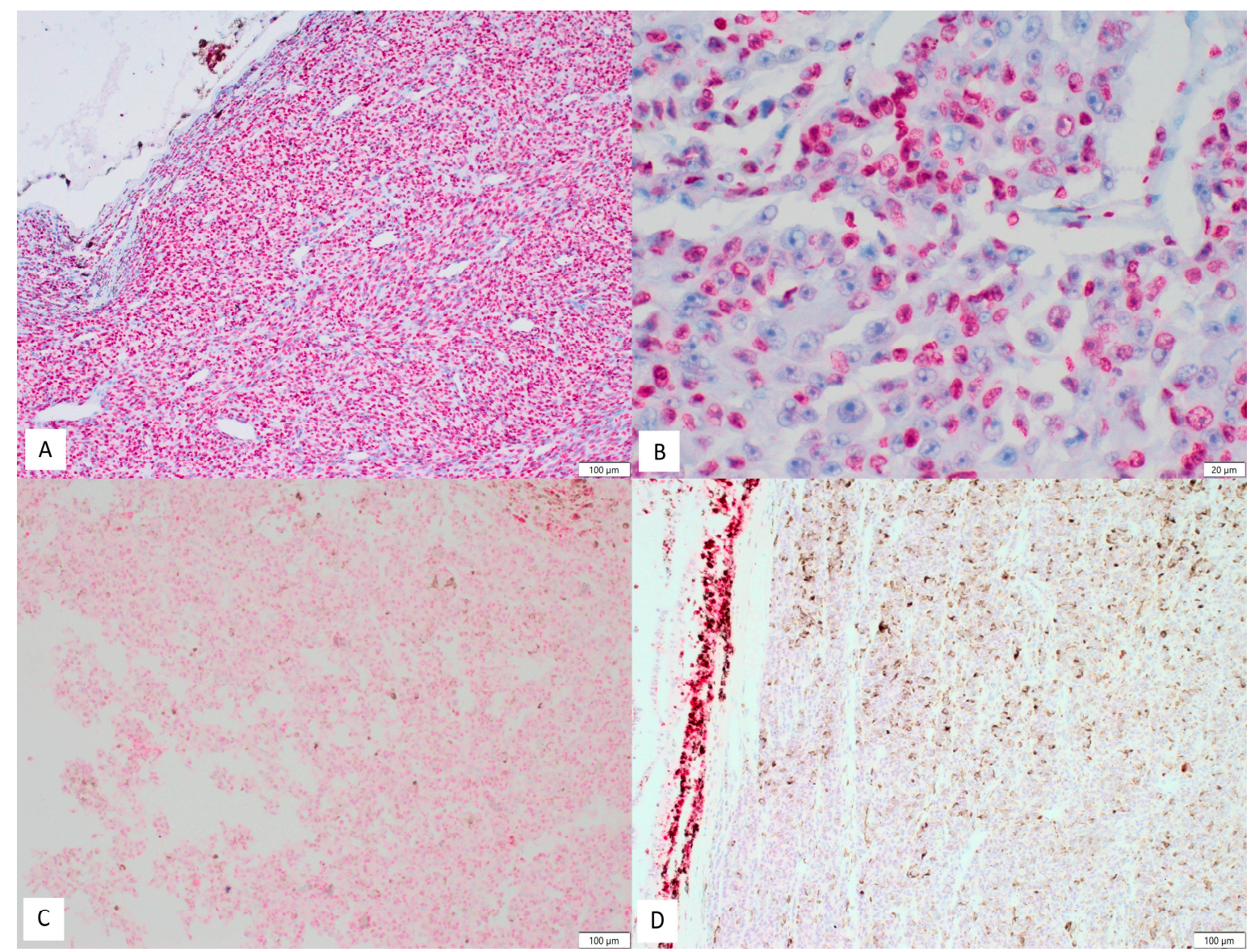

Figure 1. Examples of PARP-1 staining in uveal melanoma cells: (A) example of high expression (100 $\times)$; (B) example of high expression-intense nuclear staining visible only in about half of tumoral cells $(400 \times)$; (C) example of low expression $(100 \times)$; and $(\mathbf{D})$ complete lack of staining in tumoral cells. Focally positive internal control $(100 \times)$.

Table 1. Clinicopathological characteristics of the study group.

\begin{tabular}{cc}
\hline Clinical Factors & No (\%) \\
Gender & $36(39 \%)$ \\
Male & $55(61 \%)$ \\
Female & \\
Age & $43(47 \%)$ \\
$\leq 63$ & $48(53 \%)$ \\
$>63$ & \\
No & $54(59 \%)$ \\
Yes & $37(41 \%)$ \\
\hline iliary body involvement & $84(92 \%)$ \\
No & $7(8 \%)$ \\
Yes & $84(92 \%)$ \\
No involvement & $7(8 \%)$ \\
Yes & $13(14 \%)$ \\
\hline Irido-corneal angle involvement & $78(86 \%)$ \\
\hline No &
\end{tabular}


Table 1. Cont.

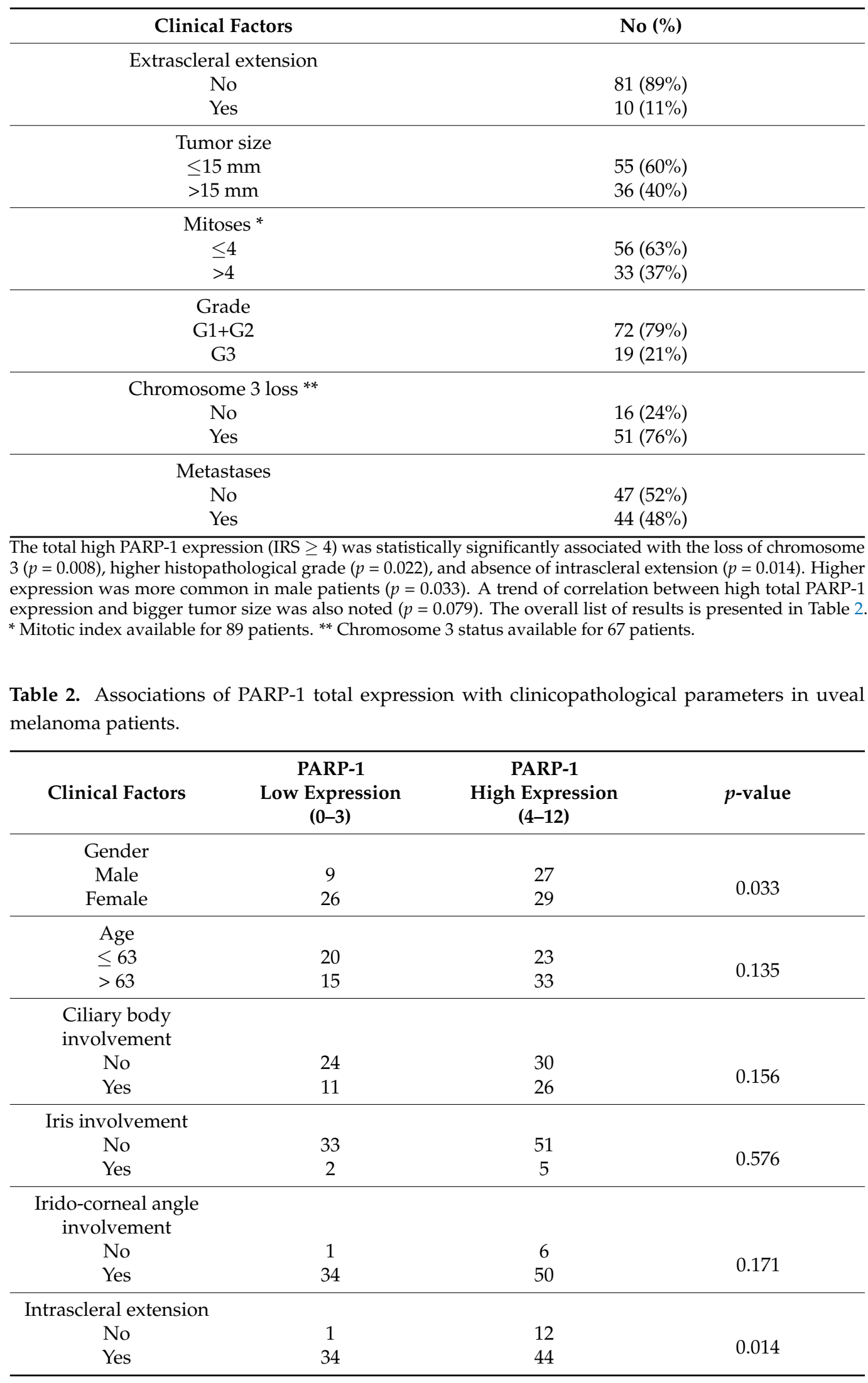


Table 2. Cont.

\begin{tabular}{cccc}
\hline Clinical Factors & $\begin{array}{c}\text { PARP-1 } \\
\text { Low Expression } \\
\mathbf{( 0 - 3 )}\end{array}$ & $\begin{array}{c}\text { PARP-1 } \\
\text { High Expression } \\
\mathbf{( 4 - 1 2 )}\end{array}$ & $p$-value \\
\hline $\begin{array}{c}\text { Extrascleral extension } \\
\text { No }\end{array}$ & 32 & 49 & 0.560 \\
Yes & 3 & 7 & \\
Tumor size & 25 & 30 & 0.079 \\
$\leq 15$ mm & 10 & 26 & \\
$>15$ mm & & & \\
Mitoses & 25 & 31 & 0.126 \\
$\leq 4$ & 10 & 23 & 0.022 \\
$>4$ & 32 & 40 & 0.008 \\
\hline Grade & 3 & 16 & \\
G1 + G2 & & & \\
G3 & 11 & 5 & 0.691 \\
\hline No & 16 & 35 & \\
Yes & 19 & 28 & \\
\hline Metastases & 16 & 28 & \\
No & & & \\
Yes & & & \\
\hline
\end{tabular}

The high intensity of the reaction was statistically significantly associated with the male gender $(p=0.036)$, absence of intrascleral extension $(p=0.025)$, bigger tumor size $(p=0.039)$, and more frequent chromosome 3 loss $(p=0.017)$. Table 3 summarizes the results for statistically significant correlations of reaction intensity.

Table 3. Statistically significant correlations of intensity of reaction against PARP-1 with clinicopathological parameters.

\begin{tabular}{cccc}
\hline Clinical Factors & $\begin{array}{c}\text { PARP-1 } \\
\text { Low Intensity } \\
(\mathbf{0}-\mathbf{1})\end{array}$ & $\begin{array}{c}\text { PARP-1 } \\
\text { High Intensity } \\
\mathbf{( 2 - 3 )}\end{array}$ & $p$-value \\
\hline Gender & 8 & 28 & \\
Male & 24 & 31 & 0.036 \\
Female & 1 & & \\
\hline Intrascleral extension & 31 & 12 & 0.025 \\
No & & 47 & 0.039 \\
Yes & 23 & 32 & \\
Tumor size & 9 & 27 & 0.017 \\
$\leq 15$ mm & & & \\
\hline 15 mm & 10 & 6 & \\
\hline Chromosome 3 loss & 15 & 36 & \\
No & &
\end{tabular}

A high percentage of positive cells were associated with bigger tumor size $(p=0.036)$, higher histopathological grade $(p=0.024)$, and more frequent chromosome 3 loss $(p=0.033)$. Table 4 summarizes the results for statistically significant correlations of percentage of positive cells. 
Table 4. Statistically significant correlations of percentage of positive cells with clinicopathological parameters.

\begin{tabular}{cccc}
\hline Clinical Factors & $\begin{array}{c}\text { PARP-1 } \\
\text { low percentage } \\
\mathbf{( 0 - 2 )}\end{array}$ & $\begin{array}{c}\text { PARP-1 } \\
\text { high percentage } \\
\mathbf{( 3 - 4 )}\end{array}$ & $p$-value \\
\hline Tumor size & 33 & 22 & \\
$\leq 15 \mathrm{~mm}$ & 14 & 22 & 0.036 \\
$>15 \mathrm{~mm}$ & & & 0.024 \\
\hline Grade & 40 & 32 & \\
G1 + G2 & 7 & 12 & 0.033 \\
G3 & 11 & 5 & \\
\hline Chromosome 3 loss & 24 & 27 & \\
No & & & \\
Yes & & & \\
\hline
\end{tabular}

High percentage of positive cells was significantly associated with shorter overall survival time $(p=0.008)$ (Figure 2A). High reaction intensity tended to decrease the likelihood of overall survival (OS) in patients with uveal melanoma ( $p=0.072$ ) (Figure 2B). A similar association occurred in the case of total high expression of PARP-1 (IRS $\geq 4$ ) $(p=0.089)$ (Figure 2C). High percentage of positive cells, high reaction intensity, and total high expression significantly shortened disease-free survival time (DFS) $(p=0.012, p=0.028$, and $p=0.039$, respectively) (Figure $3 \mathrm{~A}-\mathrm{C}$ ).

\section{Discussion}

Uveal melanoma is a relatively rare disease, but it is a significant problem in ophthalmic practice, especially due to the high mortality rate and the lack of effective treatment methods in the advanced stage. New prognostic factors are constantly being sought to more precisely define the risk of disease progression. It is also important to look for new target points for therapy. An additional problem is that the biology of uveal melanoma significantly differs from that of cutaneous melanoma. For this reason, it is not possible to use regimens that work well in cutaneous melanoma in uveal melanoma. In recent years, PARP-1 functioning in different diseases became an attractive research area. The role of PARP-1 in the processes of DNA repair and regulation of inflammation makes the determination of its expression particularly useful in cancer and autoimmune diseases.

Several studies have shown that many tumors exhibit an elevated level of PARP-1 expression, and overexpression is often associated with disease progression. Moreover, loss of PARP-1 in mouse models may decrease tumor development [17]. Possibly PARP-1 inhibition can suppress damaged DNA repair and improve tumor killing. On the other hand, PARP-1 knockout mice after exposure to radiation damage showed an increased risk of developing other tumors - in the cerebellum and the skin. This is because PARP-1 inhibition may unmask recessive mutations in tumor suppressor genes [22]. Moreover, PARP-1 may have an opposite effect on the development of the disease, depending on the mechanism of its formation. For example, PARP-1 can protect against colorectal tumor formation and at the same time promoting inflammation-driven progression of these tumors [23]. Another aspect is the importance of PARP-1 expression depending on the severity of the disease. One study in gastric cancer patients showed that high PARP-1 expression was associated with poor prognosis, but only in patients with a more advanced disease stage. Patients with an advanced TNM stage (III-IV) and high PARP-1 expression had significantly reduced DFS and OS. This association was not present in patients with early TNM stage (I-II) [24]. Another relationship was found in breast cancer. High PARP-1 expression was correlated with poor prognosis in lymph node negative early breast cancer $[25,26]$. In addition, in more advanced stages of breast cancer, high PARP-1 expression helped in predicting survival: it correlated with shorter DFS and OS and increase risk of recurrence [27]. 

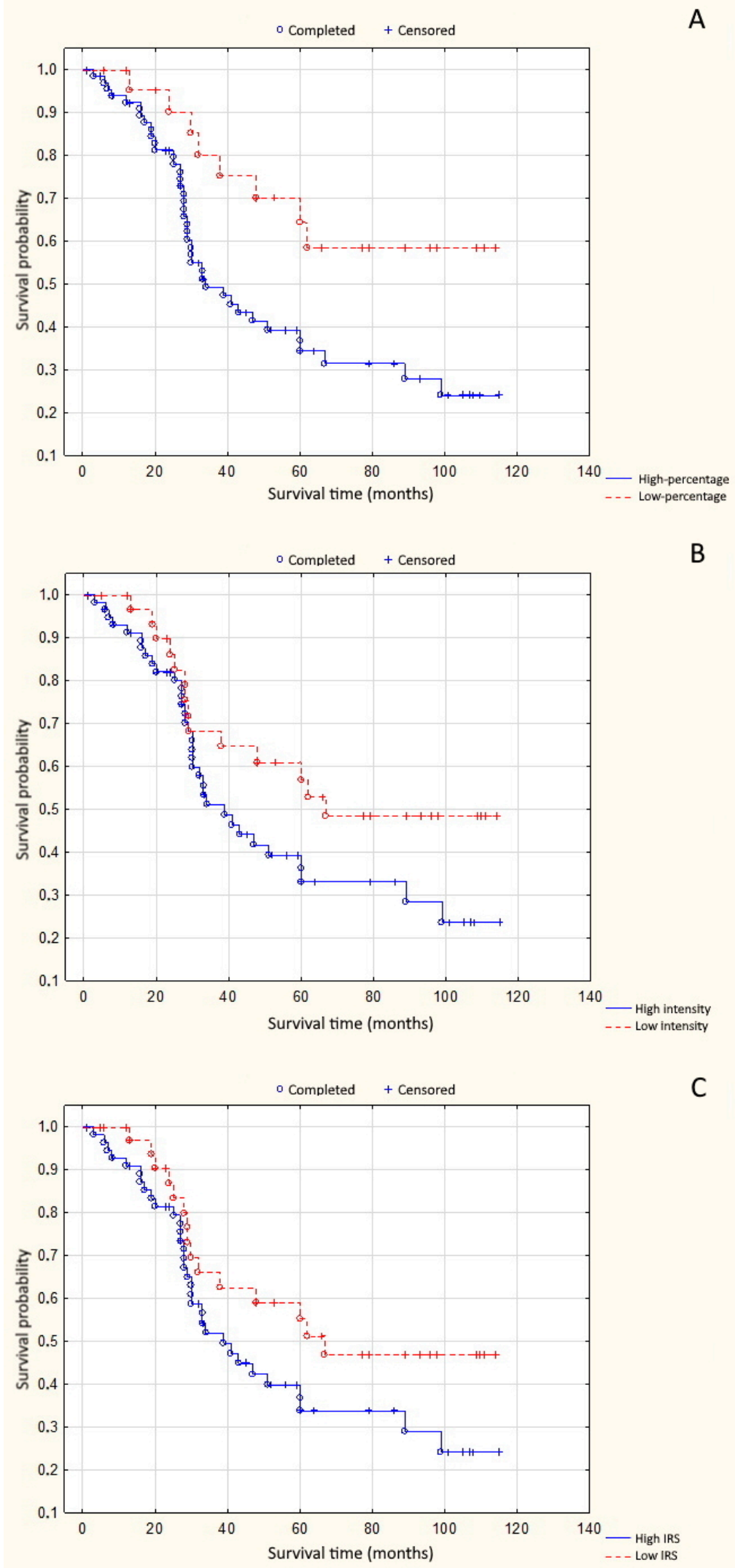

Figure 2. (A) Correlation between PARP-1 percentage of positive cells and overall survival time $(p=0.008)$; (B) correlation between PARP-1 reaction intensity and overall survival time $(p=0.072)$; and $(C)$ correlation between PARP-1 total expression and overall survival time $(p=0.089)$. 

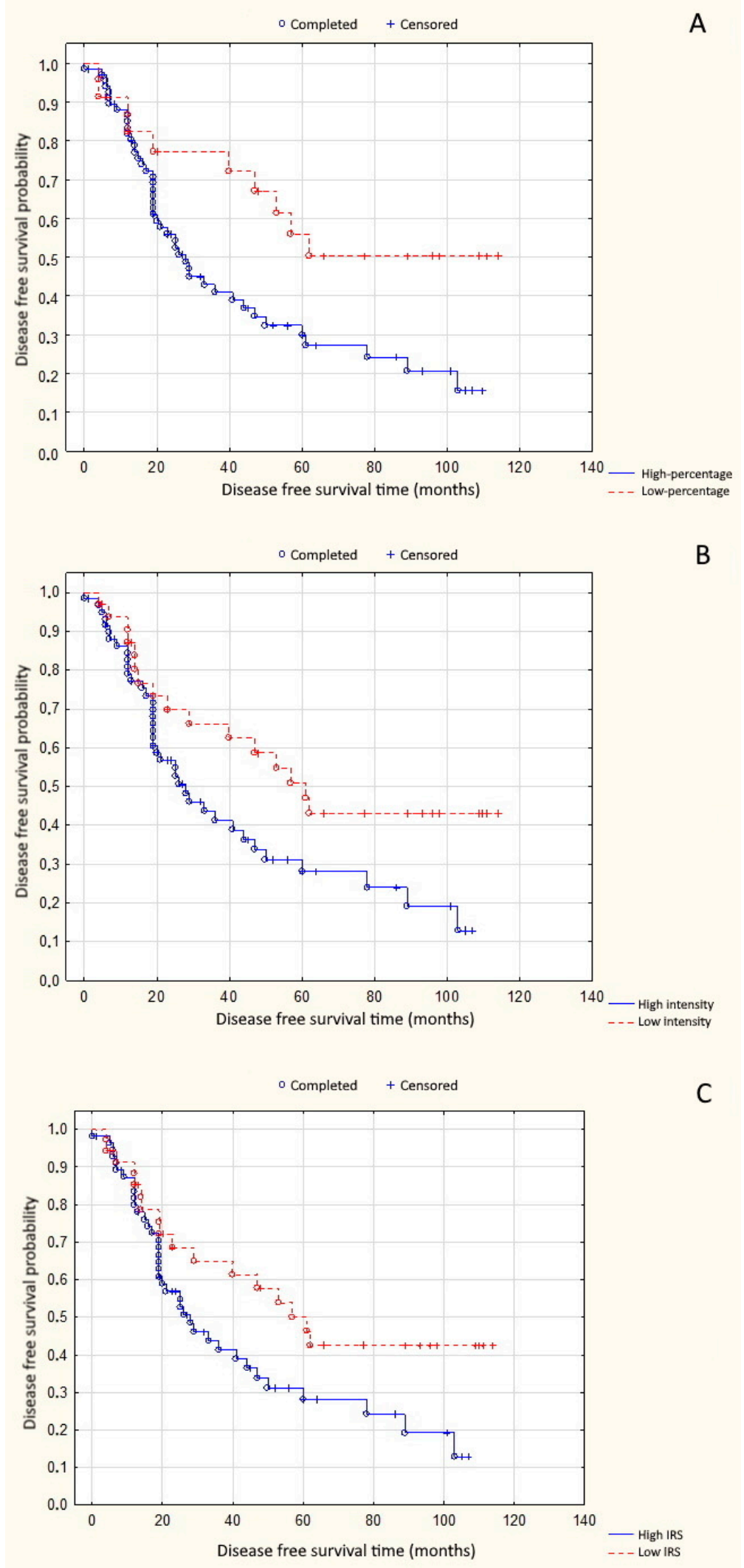

Figure 3. (A) Correlation between PARP-1 percentage of positive cells and disease-free survival time ( $p=0.012)$; (B) correlation between PARP-1 reaction intensity and disease-free survival time $(p=0.028)$; and $(\mathbf{C})$ correlation between PARP-1 total expression and disease-free survival time $(p=0.039)$. 
The tissues used in our study were obtained from eyes after enucleation. This procedure is performed only in advanced disease cases [4]. Therefore, in the studied cases, we showed a significant relationship between OS and DFS in patients with advanced UM. Investigating whether PARP-1 expression in cases of early UM affects the prognosis is problematic, because, due to the small size of the tumor and its frequent location in the posterior part of the eyeball, obtaining tissues for histopathological examination is practically impossible.

There are many reports on the possible use of PARP-1 expression as a prognostic factor in various neoplasms, in which the severity of the disease does not play a significant role. Thus, an increased level of PARP-1 expression was observed in lung, prostate, uterus, and ovarian cancers [28,29]. High PARP-1 expression alone and in combination with the expression of other DNA repair molecules $(\gamma \mathrm{H} 2 \mathrm{AX}, \mathrm{BRCA} 1$, and BRCA2) is prognostic factor for shorter survival in soft tissue sarcoma patients [30]. PARP-1 expression is also increased in colon adenoma and carcinoma [31]. The evaluation of PARP-1 expression as a prognostic factor in mucosal melanomas has also been shown [32]. Our results are in line with the general trend. The demonstrated associations with recognized prognostic factors-loss of chromosome 3, tumor size, and histopathological grade-indicates that high PARP-1 expression can be considered an unfavorable prognostic factor in UM.

There are only a few reports in the literature published so far on the role of PARP- 1 in uveal melanoma. In one study, a small group of tumors $(n=12)$ were examined and PARP expression was observed with different intensity [33]. Another study analyzed PARP-1 expression in the T97, T98, T108, and T115 cell lines. The level of expression varied with changing distinctive tumorigenic properties [34].

Another noteworthy issue is the possibility of using PARP-1 as a potential target for therapy. PARP-1 inhibitors are mentioned as one of the treatment options for cancer-as they influence the stabilization of the genome and repair of DNA mutations [35]. PARP-1 inhibitors are already used in the treatment of certain types of cancers-ovarian, breast, and prostate [36,37]. In oral squamous cell carcinomas, overexpression of PARP-1 may serve as novel predictive biomarker for therapy responsiveness [38]. Research is also underway on the use of PARP-1 inhibitor in treatment other diseases, among others multiple sclerosis, rheumatoid arthritis, myocardial infarction, stroke, acute neuroinjury, and Parkinson's disease $[39,40]$. Our demonstrated high PARP-1 expression in the examined tissues indicates a possible target for pharmacological therapy in UM. This study could be valuable for future introduction of new treatment regimens as it has already been shown on a UM patient-derived xenografts (PDXs) that PARP inhibitor olaparib significantly increased the efficacy of the alkylating agent dacarbazine in UM [41]. These results represent a very promising subject for further research into the treatment of UM.

\section{Conclusions}

Despite the great interest in the role of PARP in cancer formation, its role in UM is relatively poorly studied with only a few published reports. Our study shows that PARP-1 expression can be useful prognostic and predictive biomarker in UM. This study could also be valuable for future introducing new treatment regimens.

Author Contributions: Conceptualization, P.G., P.D., J.K., S.T., R.K. and M.G.; methodology, P.G., S.T. and J.K.; formal analysis, P.G.; investigation, M.G., S.T., J.K., N.C., S.G., P.D., R.K. and P.G.; resources, M.G., S.T., J.K., N.C., S.G., P.D., R.K. and P.G.; writing-original draft preparation, M.G. and P.G.; writing-review and editing, M.G., S.T., J.K., N.C., S.G., P.D., R.K. and P.G.; visualization, P.G. and P.D.; supervision, S.T., J.K. and R.K.; and funding acquisition, P.D. All authors have read and agreed to the published version of the manuscript.

Funding: This research was financed through a statutory subsidy by the Polish Minister of Science and Higher Education as a part of grant SUB.B130.20.022 (record numbers in the Simple system). 
Institutional Review Board Statement: The study was conducted according to the guidelines of the Declaration of Helsinki, and approved by the Institutional Review Board of the Wroclaw Medical University, Poland (KB-508/2019—approval for statutory subsidy).

Informed Consent Statement: Due to the retrospective nature of the studies and the lack of impact on the treatment of patients, it was not necessary to obtain informed consent.

Data Availability Statement: The data presented in this study are available on request from the corresponding author.

Conflicts of Interest: The authors declare no conflict of interest

\section{References}

1. Maheshwari, A.; Finger, P.T. Cancers of the eye. Cancer Metastasis Rev. 2018, 37, 677-690. [CrossRef] [PubMed]

2. Carvajal, R.D.; Schwartz, G.K.; Tezel, T.; Marr, B.; Francis, J.H.; Nathan, P.D. Metastatic disease from uveal melanoma: Treatment options and future prospects. Br. J. Ophthalmol. 2017, 101, 38-44. [CrossRef] [PubMed]

3. Kivela, T.; Simpson, R.E.; Grossniklaus, H.E. Uveal Melanoma. In AJCC Cancer Staging Manual, 8th ed.; Springer: New York, NY, USA, 2016; pp. 805-817.

4. Yang, J.; Manson, D.K.; Marr, B.P.; Carvajal, R.D. Treatment of uveal melanoma: Where are we now? Ther. Adv. Med. Oncol. 2018, 10, 1-17. [CrossRef] [PubMed]

5. Jubin, T.; Kadam, A.; Jariwala, M.; Bhatt, S.; Sutariya, S.; Gani, A.R.; Gautam, S.; Begum, R. The PARP family: Insights into functional aspects of poly (ADP-ribose) polymerase-1 in cell growth and survival. Cell Prolif. 2016, 49, 421-437. [CrossRef]

6. Izhar, L.; Adamson, B.; Ciccia, A.; Lewis, J.; Pontano-Vaites, L.; Leng, Y.; Liang, A.C.; Westbrook, T.F.; Harper, J.W.; Elledge, S.J. A Systematic Analysis of Factors Localized to Damaged Chromatin Reveals PARP-Dependent Recruitment of Transcription Factors. Cell Rep. 2015, 11, 1486-1500. [CrossRef] [PubMed]

7. Li, M.; Yu, X. The role of poly(ADP-ribosyl)ation in DNA damage response and cancer chemotherapy. Oncogene 2015, 34, 3349-3356. [CrossRef]

8. Timinszky, G.; Till, S.; Hassa, P.O.; Hothorn, M.; Kustatscher, G.; Nijmeijer, B.; Colombelli, J.; Altmeyer, M.; Stelzer, E.H.; Scheffzek, K. and Hottiger, M.O. A macrodomain-containing histone rearranges chromatin upon sensing PARP1 activation. Nat. Struct. Mol. Biol. 2009, 16, 923-929. [CrossRef]

9. Ahel, D.; Hořejší, Z.; Wiechens, N.; Polo, S.E.; Garcia-Wilson, E.; Ahel, I.; Flynn, H.; Skehel, M.; West, S.C.; Jackson, S.P.; et al. Poly(ADP-ribose)-dependent regulation of DNA repair by the chromatin remodeling enzyme ALC1. Science 2009, 325, 1240-1243. [CrossRef]

10. Altmeyer, M.; Toledo, L.; Gudjonsson, T.; Grøfte, M.; Rask, M.B.; Lukas, C.; Akimov, V.; Blagoev, B.; Bartek, J.; Lukas, J. The chromatin scaffold protein SAFB1 renders chromatin permissive for DNA damage signaling. Mol. Cell 2013, 52, 206-220. [CrossRef]

11. Pazzaglia, S.; Pioli, C. Multifaceted Role of PARP-1 in DNA Repair and Inflammation: Pathological and Therapeutic Implications in Cancer and Non-Cancer Diseases. Cells 2019, 9, 41. [CrossRef]

12. Bryant, H.E.; Helleday, T. Inhibition of poly (ADP-ribose) polymerase activates ATM which is required for subsequent homologous recombination repair. Nucleic Acids Res. 2006, 34, 1685-1691. [CrossRef] [PubMed]

13. Patel, A.G.; Sarkaria, J.N.; Kaufmann, S.H. Nonhomologous end joining drives poly(ADP-ribose) polymerase (PARP) inhibitor lethality in homologous recombination-deficient cells. Proc. Natl. Acad. Sci. USA 2011, 108, 3406-3411. [CrossRef] [PubMed]

14. Soldani, C.; Scovassi, A.I. Poly(ADP-ribose) polymerase-1 cleavage during apoptosis: An update. Apoptosis 2002, 7, 321-328. [CrossRef] [PubMed]

15. Sosna, J.; Voigt, S.; Mathieu, S.; Lange, A.; Thon, L.; Davarnia, P.; Herdegen, T.; Linkermann, A.; Rittger, A.; Chan, F.K.M.; et al. TNF-induced necroptosis and PARP-1-mediated necrosis represent distinct routes to programmed necrotic cell death. Cell. Mol. Life Sci. 2014, 71, 331-348. [CrossRef]

16. Cohen, M. Interplay between compartmentalized NAD+ synthesis and consumption: A focus on the PARP family. Genes Dev. 2020, 34, 254-262. [CrossRef]

17. Nakagawa, Y.; Sedukhina, A.; Okamoto, N.; Nagasawa, S.; Suzuki, N.; Ohta, T.; Hattori, H.; Roche-Molina, M.; Narváez, A.; Jeyasekharan, D.; et al. NF-kB signaling mediates acquired resistance after PARP inhibition. Oncotarget 2015, 6, 3825-3839. [CrossRef]

18. Martín-Oliva, D.; O’Valle, F.; Munoz-Gamez, J.A.; Valenzuela, M.T.; Nunez, M.I.; Aguilar, M.; de Almodovar, J.R.; del Moral, R.G.; Oliver, F.J. Crosstalk between PARP-1 and NF-кB modulates the promotion of skin neoplasia. Oncogene 2004, 23, 5275-5283. [CrossRef]

19. Specht, E.; Kaemmerer, D.; Sänger, J.; Wirtz, R.M.; Schulz, S.; Lupp, A. Comparison of immunoreactive score, HER2/neu score and $\mathrm{H}$ score for the immunohistochemical evaluation of somatostatin receptors in bronchopulmonary neuroendocrine neoplasms. Histopathology 2015, 67, 368-377. [CrossRef] 
20. Donizy, P.; Halon, A.; Surowiak, P.; Pietrzyk, G.; Kozyra, C.; Matkowski, R. Correlation between PARP-1 immunoreactivity and cytomorphological features of parthanatos, a specific cellular death in breast cancer cells. Eur. J. Histochem. 2013, 57, 237-240. [CrossRef]

21. Fedchenko, N.; Reifenrath, J. Different approaches for interpretation and reporting of immunohistochemistry analysis results in the bone tissue-A review. Diagn. Pathol. 2014, 9, 221. [CrossRef]

22. Tanori, M.; Mancuso, M.; Pasquali, E.; Leonardi, S.; Rebessi, S.; Di Majo, V.; Guilly, M.N.; Giangaspero, F.; Covelli, V.; Pazzaglia, S.; et al. PARP-1 cooperates with Ptc1 to suppress medulloblastoma and basal cell carcinoma. Carcinogenesis 2008, 29, 1911-1919. [CrossRef] [PubMed]

23. Dörsam, B.; Seiwert, N.; Foersch, S.; Stroh, S.; Nagel, G.; Begaliew, D.; Diehl, E.; Kraus, A.; McKeague, M.; Minneker, V.; et al. PARP-1 protects against colorectal tumor induction, but promotes inflammation-driven colorectal tumor progression. Proc. Natl. Acad. Sci. USA 2018, 115, E4061-E4070. [CrossRef] [PubMed]

24. Liu, Y.; Zhang, Y.; Zhao, Y.; Gao, D.; Xing, J.; Liu, H. High PARP-1 expression is associated with tumor invasion and poor prognosis in gastric cancer. Oncol. Lett. 2016, 12, 3825-3835. [CrossRef] [PubMed]

25. Donizy, P.; Pietrzyk, G.; Halon, A.; Kozyra, C.; Gansukh, T.; Lage, H. Surowiak, P.; Matkowski, R. Nuclear-cytoplasmic PARP-1 expression as an unfavorable prognostic marker in lymph node-negative early breast cancer: 15-year follow-up. Oncol. Rep. 2014, 31, 1777-1787. [CrossRef] [PubMed]

26. Rojo, F.; Garcia-Parra, J.; Zazo, S.; Tusquets, I.; Ferrer-Lozano, J.; Menendez, S.; Eroles, P.; Chamizo, C.; Servitja, S.; Ramirez-Merino, N.; et al. Nuclear PARP-1 protein overexpression is associated with poor overall survival in early breast cancer. Ann. Oncol. 2012, 23, 1156-1164. [CrossRef] [PubMed]

27. von Minckwitz, G.; Müller, B.M.; Loibl, S.; Budczies, J.; Hanusch, C.; Darb-Esfahani, S.; Hilfrich, J.; Weiss, E.; Huober, J.; Blohmer, J.U.; et al. Cytoplasmic poly(adenosine diphosphate-ribose) polymerase expression is predictive and prognostic in patients with breast cancer treated with neoadjuvant chemotherapy. J. Clin. Oncol. 2011, 29, 2150-2157. [CrossRef]

28. Ossovskaya, V.; Koo, I.C.; Kaldjian, E.P.; Alvares, C.; Sherman, B.M. Upregulation of Poly (ADP-Ribose) Polymerase-1 (PARP1) in Triple-Negative Breast Cancer and Other Primary Human Tumor Types. Genes Cancer 2010, 1, 812-821. [CrossRef]

29. Salemi, M.; Galia, A.; Fraggetta, F.; La Corte, C.; Pepe, P.; La Vignera, S.; Improta, G.; Bosco, P.; Calogero, A.E. Poly (ADP-ribose) polymerase 1 protein expression in normal and neoplastic prostatic tissue. Eur. J. Histochem. 2013, 57, 80-82. [CrossRef]

30. Kim, K.M.; Moon, Y.J.; Park, S.H.; Park, H.J.; Wang, S.I.; Park, H.S.; Lee, H.; Kwon, K.S.; Moon, W.S.; Lee, D.G.; et al. Individual and Combined Expression of DNA Damage Response Molecules PARP1, $\gamma$ H2AX, BRCA1, and BRCA2 Predict Shorter Survival of Soft Tissue Sarcoma Patients. PLoS ONE 2016, 11, e0163193. [CrossRef]

31. Dziaman, T.; Ludwiczak, H.; Ciesla, J.M.; Banaszkiewicz, Z.; Winczura, A.; Chmielarczyk, M.; Wisniewska, E.; Marszalek, A.; Tudek, B.; Olinski, R. PARP-1 Expression is Increased in Colon Adenoma and Carcinoma and Correlates with OGG1. PLoS ONE 2014, 9, e115558. [CrossRef]

32. Donizy, P.; Wu, C.L.; Mull, J.; Fujimoto, M.; Chłopik, A.; Peng, Y.; Shalin, S.C.; Selim, M.A.; Puig, S.; Fernandez-Figueras, M.T.; et al. Up-Regulation of PARP1 Expression Significantly Correlated with Poor Survival in Mucosal Melanomas. Cells 2020, 9 , 1135. [CrossRef] [PubMed]

33. Géhl, Z.; Bai, P.; Bodnár, E.; Emri, G.; Remenyik, É.; Németh, J.; Gergely, P.; Virág, L.; Szabó, É. Poly(ADP-ribose) in the skin and in melanomas. Histol. Histopathol. 2012, 27, 651-659. [PubMed]

34. Molloy-Simard, V.; St-Laurent, J.F.; Vigneault, F.; Gaudreault, M.; Dargis, N.; Guérin, M.C.; Leclerc, S.; Morcos, M.; Black, D.; Molgat, Y.; et al. Altered expression of the Poly(ADP-Ribosyl)ation enzymes in uveal melanoma and regulation of PARG gene expression by the transcription factor ERM. Investig. Ophthalmol. Vis. Sci. 2012, 53, 6219-6231. [CrossRef] [PubMed]

35. Hanahan, D.; Weinberg, R.A. Leading Edge Review Hallmarks of Cancer: The Next Generation. Cell 2011, 144, 646-674. [CrossRef]

36. Yuan, B.; Ye, N.; Song, S.-S.; Wang, Y.-T.; Song, Z.; Chen, H.-D. Poly(ADP-ribose)polymerase (PARP) inhibition and anticancer activity of simmiparib, a new inhibitor undergaoing clinical trials. Cancer Lett. 2017, 386, 47-56. [CrossRef] [PubMed]

37. Pezaro, C. PARP inhibitor combinations in prostate cancer. Ther. Adv. Med. Oncol. 2012, 12, 1758835919897537. [CrossRef]

38. Mascolo, M.; Ilardi, G.; Romano, M.F.; Celetti, A.; Siano, M.; Romano, S.; Luise, C.; Merolla, F.; Rocco, A.; Vecchione, M.L.; et al. Overexpression of chromatin assembly factor-1 p60, poly(ADP-ribose) polymerase 1 and nestin predicts metastasizing behaviour of oral cancer. Histopathology 2012, 61, 1089-1105. [CrossRef]

39. Berger, N.; Bessson, V.; Boulares, H.; Burkle, A.; Chiarugi, A. Opportunities for the repurposing of PARP inhibitors for the therapy of non-oncological diseases. Br. J. Pharmacol. 2018, 172, 192-222. [CrossRef]

40. Meira, M.; Sievers, C.; Hoffmann, F.; Bodmer, H.; Derfuss, T.; Kuhle, J.; Haghikia, A.; Kappos, L.; Lindberg, R.L. PARP-1 deregulation in multiple sclerosis. Mult. Scler. J. Exp. Transl. Clin. 2019, 5, 1-20. [CrossRef]

41. De Koning, L.; Decaudin, D.; El Botty, R.; Nicolas, A.; Carita, G.; Schuller, M.; Ouine, B.; Cartier, A.; Naguez, A.; Fleury, J.; et al. Parp inhibition increases the response to chemotherapy in uveal melanoma. Cancers 2019, 11, 751. [CrossRef] 